The Egyptian Journal of Hospital Medicine (April 2019) Vol. 75 (2), Page 2312-2318

\title{
Comparison Between Intravitreal Ranibizumab Injection, Corticosteroid Implants and Intravitreal Triamcinolone Acetonide injection In Treatment of Noninfectious Uveitic Macular Edema Ahmed N. Elsayed \\ Department of Ophthalmology, Faculty of Medicine, Al-Azhar University, Cairo, Egypt
}

\begin{abstract}
Background: Uveitis is a broad term for inflammation involving the eye. It is classified according to the location of the inflammatory process either anterior, intermediate, posterior or panuveitis. Uveitis can be secondary to an infectious etiology, such as tuberculosis, toxocara canis, toxoplasmosis, herpes virus, Lyme, and syphilis.

Purpose: comparing the efficacy and safety of intravitreal ranibizumab injection, corticosteroid implants and Intravitreal triamcinolone acetonide (IVTA) injection in treatment of noninfectious uveitic macular edema.

Patients and Methods: A prospective study was conducted in Al-Azhar University Hospitals (El-Hussein and BabElsheryia Hospitals). A total of 60 eyes of 45 uveitic patients were recruited in this study. First group; 20 eyes undergo intravitreally injection with ranibizumab $0.5 \mathrm{mg}(0.05 \mathrm{ml})$, one dose per month (six doses). Second group; 20 eyes undergo corticosteroid implants. Third group 20 eyes undergo IVTA injection.

Results: All patients included in this study completed the period of follow up (six months) in group 1 Visual acuity (VA) improved and central macular thickness (CMT) decreased slightly but not significantly after 1 month to 1.35 \pm 0.25 and $365.3 \pm 185.5 \mu \mathrm{M}$, respectively. In group 2; VA improved and CMT decreased after 1 month to $1.75 \pm 0.2$ and $470.45 \pm 175.20 \mu \mathrm{M}$, respectively. In group 3; VA improved and CMT decreased slightly after 1 month to 2.15 \pm 0.22 and $460.45 \pm 185.45 \mu \mathrm{M}$, respectively, an increase of intra ocular pressure (IOP) between $6 \mathrm{mmHg}$ and 15 mmHg was maintained in 16 of 20 eyes (80\%) at 1 months and was maintained in 4 of 20 eyes at 3 months (20\%).

Conclusion: Intravitreal injection can be used as a single therapy to treat uveitic ME secondary to noninfectious uveitis. With a variety of intravitreal therapeutic agents available for treatment of uveitic ME in this study (Intravitreal ranibizumab injection, corticosteroid implants and IVTA) and each drug having its own advantages and disadvantages, the final treatment should be individualized based on the severity of disease, risk /benefit ratio of each therapy and choice of the patient.
\end{abstract}

Keywords: Ranibizumab, Dexamethasone, IVTA, uveitic macular oedema.

\section{INTRODUCTION}

Uveitis is a broad term for inflammation involving the eye. It is classified according to the location of the inflammatory process either anterior, intermediate, posterior or panuveitis ${ }^{(\mathbf{1})}$. Uveitis can be secondary to an infectious etiology, such as tuberculosis, toxocara canis, toxoplasmosis, herpes virus, Lyme, and syphilis. Ocular inflammation can also be associated with an underlying systemic condition, including juvenile idiopathic arthritis (JIA), sarcoidosis, tubulointerstitial nephritis and uveitis (TINU), inflammatory bowel disease, Vogt-KoyonagiHarada (VKH) and Bechet's disease frequently; however, uveitis is not associated with an underlying condition and is termed "idiopathic" (2).

Uveitis is one of the major causes of visual morbidity, with a reported prevalence of 38-714 cases per 100,000 . It is responsible for $10 \%-15 \%$ blindness in the developed world. It predominantly affects the younger population, and the consequent economic blindness imposes a greater burden on society and healthcare ${ }^{(3)}$.
Cystoid ME (CME) may progressively damage the macular photoreceptors and may lead to complications such as macular ischemia, macular cyst, or hole formation resulting in nonreversible visual acuity loss. Development of an epiretinal membrane is also a consequence of chronic macular edema. Thus it is important to treat macular edema early. Further chronic macular edema may become more difficult to treat. Refractory macular edema usually occurs in patients with chronic or recurrent uveitis ${ }^{(4)}$.

Corticosteroid remains the first-line therapy for the management of uveitis. Corticosteroids are effective in treating $\mathrm{ME}$ due to its potent anti-inflammatory properties by preventing leukocyte migration, stabilizing endothelial cell tight junctions which reduces cellular and fluid extravasation, and also inhibiting synthesis of vascular endothelial growth factor (VEGF), prostaglandins, and proinflammatory cytokines ${ }^{(\mathbf{5})}$.

Triamcinolone acetonide (TA) is the most widely used corticosteroid for the treatment of uveitic CME. When TA injected intravitreally, it has a mean half-life 
of 18.6 days in non vitrectomized eyes and 3.2 days in post vitrectomized eyes ${ }^{(6)}$.

Dexamethasone (DEX) is a water-soluble, synthetic glucocorticoid that is three times more potent as compared to TA. However, being a small molecule, it is rapidly cleared from the vitreous, with an estimated vitreal half-life of $5.5 \mathrm{~h}$ in human ${ }^{(7)}$.

DEX implant (Ozurdex, Allergan, Inc., Irvine, CA) is an intravitreal, biodegradable, sustained-release rod-shaped implant approved by the US Food and Drug Administration (US-FDA) in phase-wise manner for the treatment of ME secondary to retinal vein occlusion, noninfectious uveitis, and diabetic ME. It is composed of polylactic acid and polyglycolic acid polymers that slowly undergoes hydrolysis and gradually releases 700 $\mu \mathrm{g}$ of drug inside the vitreous cavity over a 6-month period, reducing the need for frequent intravitreal injections ${ }^{(8)}$.

Both bevacizumab (BVZ) and ranibizumab (RBZ) have been tried in the treatment on ME associated with noninfectious uveitis. BVZ is a full-length, recombinant, humanized monoclonal antibody against all subtypes of VEGF, and despite having a potentially immunogenic property, it seems to be well tolerated in uveitic eyes with immunogenic predisposition. Available as a preservative-free solution, BVZ is free of any retinotoxic component (9). RBZ is a recombinant, humanized monoclonal antibody antigen-binding fragment $(\mathrm{Fab})$ which neutralizes all VEGF isoforms and bioactive fragments It has 100 times higher affinity for VEGF than bevacizumab ${ }^{(\mathbf{1 0})}$.

\section{AIM OF THE WORK}

It is to compare the efficacy and safety of intravitreal ranibizumab injection, corticosteroid implants and IVTA injection in treatment of noninfectious uveitic macular edema.

\section{PATIENT AND METHOD}

A prospective study was conducted in, Al-Azhar University Hospitals (El-Hussein and Bab-Elsheryia Hospitals) this prospective study was performed from January 2016 to July 2017 ,

The study was approved by the Ethics Committee at Faculty of Medicine, Al-Azhar University. A total 60 eyes of 45 uveitic patients were recruited in this study. First group; 20 eyes undergo intravitreally injection with ranibizumab $0.5 \mathrm{mg}(0.05$ $\mathrm{ml}$ ), one dose per month (six doses). Second group; 20 eyes undergo corticosteroid implants. Third group 20 eyes undergo IVTA.
All Patients having macular edema (ME) owing to uveitis were included. Patients with a baseline (CMT) of at least $250 \mu \mathrm{M}$ and without any neovascularization were included.

All patients underwent thorough systemic evaluation including cardiovascular assessment, blood pressure measurement. All patients underwent a complete ophthalmologic evaluation at baseline, 1 month, 3 months, and 6 months. During follow-up, examinations included best-corrected visual acuity (BCVA) testing using E-letter chart, slit-lamp, measuring IOP twice using Goldman applanation tonometry, If the measures differed by more than $2 \mathrm{mmHg}$, a third measurement was performed. If Goldman IOP could not be obtained then Tono-Pen (Mentor Ophthalmic, Norwell, MA) was used; Tono-Pen measurement were performed twice and, if the measures differed by 3 or more $\mathrm{mmHg}$, a third measurement was taken.

Optical coherence tomography (OCT) was performed at 1, 3, 6 months according to identify the extent of ME, For macular thickness evaluation, a $30 \times 30^{\circ}$ rectangle encompassing the macula was obtained, averaged to 40 frames and included 31 horizontal line scans to measure the CMT at $1 \mathrm{~mm}$ circle. Other important outcomes reported here include IOP.

All patients in group 1 received six injection 0.5 $\mathrm{mg}(0.05 \mathrm{ml})$ dose of intravitreal Lucentis one /dose per month (ranibizumab; Genentech Inc., South San Francisco, California, USA). All intravitreal injections were performed in the operating room under sterile conditions after an initial paracentesis under topical anesthesia by benoxinate $0.4 \%$ eye drops, Ranibizumab was injected intravitreally via the pars plana using a $30 \mathrm{G}$ needle.

All patients in group 2 implant dexamethasone, all implants were performed under sterile conditions, after preparation of the conjunctiva using $5 \%$ povidoneiodine solution, topical anesthetic with ropivacaine, and positioning of the blepharostat. A $700 \mu \mathrm{g}$ slow-release intravitreal dexamethasone implant (Ozurdex®) was placed in the vitreal cavity, behind the crystalline lens within $3 \pm 2$ days from baseline examination. All injections were performed in an operating room. The dexamethasone implant was inserted into the vitreous cavity through the pars plana using a customized, singleuse 22-gauge applicator. Patients were treated with a topical ophthalmic antibiotic (netilmicin sulphate) for seven days after treatment.

All patients in group 3 received two injection of Triamcinolone acetonide (TA) in dose of $4 \mathrm{mg}$ each dose per 3 months, all intravitreal injections were performed in the operating room under sterile conditions after an 
initial paracentesis under topical anesthesia by benoxinate $0.4 \%$ eye drops, TA was injected intravitreally via the pars plana using a $30 \mathrm{G}$ needle.

\section{Inclusion criteria}

The inclusion Criteria were as follows: (1) age >18 years old, (2) BCVA between 5 and 40 letters in the study eye (3) CMT $>250 \mu \mathrm{M}$.

\section{Exclusion criteria}

The exclusion criteria were as follows: (1) structural damage (including atrophy of the retinal pigment epithelium, subretinal fibrosis, laser scars," epiretinal membrane involving fovea, or organized hard exudative plaques within a 0.5 disc diameter of the center of the macula in the studied eye (2) ocular surgery in the study eye in the last six months (3) glaucoma (4) ME due to other causes than uveitic macular edema were excluded.

\section{Safety criteria}

The appearance of undesired side effects correlated with the injection, such as inflammation of the anterior chamber, lens opacity, ocular pain, or vitreous opacity was monitored. The side effects correlated with the surgical intervention such as endophthalmitis, perforation of the eye, conjunctival hemorrhage and systemic effects related to the injection were also monitored.

\section{Statistical analysis}

Recorded data were analyzed using the statistical package for social sciences, version 20.0 (SPSS Inc.,
Chicago, Illinois, USA). Quantitative data were expressed as mean \pm standard deviation (SD). Qualitative data were expressed as frequency and percentage.

\section{The following tests were done:}

Independent-samples t-test of significance was used when comparing between two means.

- Chi-square $\left(\mathrm{x}^{2}\right)$ test of significance was used in order to compare proportions between two qualitative parameters.

- The confidence interval was set to $95 \%$ and the margin of error accepted was set to 5\%. The p-value was considered significant as the following:

Probability (P-value)

- P-value <0.05 was considered significant.

- P-value $<0.001$ was considered as highly significant.

- P-value >0.05 was considered insignificant.

\section{RESULTS}

A total 60 eyes of 45 uveitic patients (43 males, 17 females) were recruited in this study. First group 20 eyes undergo intravitreally injection with ranibizumab $0.5 \mathrm{mg}(0.05 \mathrm{ml})$; one dose per month (six doses). Second group 20 eyes undergo, Corticosteroid implants Third group undergo IVTA 2 dose per 3 month.

The three treatment groups were similar regarding age, sex, type of uveitis and baseline ocular characteristics including visual acuity, ME thickness. Also there is no significant difference between groups in associated systemic diseases (Table 1). Demographics and basic characteristics in both group were summarized in Table 1 .

Table (1): Baseline characteristics of participants and eyes with uveitis by assigned treatment

\begin{tabular}{|c|c|c|c|}
\hline Characteristic & Group 1 & Group 2 & Group 3 \\
\hline Demographics & $N=126$ & $\mathrm{~N}=129$ & $\mathrm{~N}=128$ \\
\hline Age, mean years (SD) & $43.18 \pm 14.3$ & $41.4 \pm 13.5$ & $42.5 \pm 13.9$ \\
\hline Male & $14(70 \%)$ & $15(75 \%)$ & $14(70 \%)$ \\
\hline Female & $6(30 \%)$ & $5(25 \%)$ & $6(30 \%)$ \\
\hline \multicolumn{4}{|l|}{ Clinical Characteristics } \\
\hline Unilateral uveitis & $16(80 \%)$ & $15(75 \%)$ & $14(70 \%)$ \\
\hline \multicolumn{4}{|l|}{ Site of uveitis } \\
\hline Intermediate & $2(10 \%)$ & $3(15 \%)$ & $2(10 \%)$ \\
\hline Posterior or Panuveitis & $18(90 \%)$ & $17(85 \%)$ & $18(90 \%)$ \\
\hline \multicolumn{4}{|l|}{ Systemic disease } \\
\hline Diabetes mellitus & $14(70 \%)$ & $16(80 \%)$ & $14(70 \%)$ \\
\hline Hypertension & $8(40 \%)$ & $11(55 \%)$ & $13(65 \%)$ \\
\hline
\end{tabular}

The etiology of uveitis was established in $75 \%$ of all cases in the study and not established in $25 \%$ in all group (Table2). 
Table 2: Causes of uveitis

\begin{tabular}{|l|l|l|l|}
\hline & Group 1 & Group 2 & Group 3 \\
\hline Behçet disease & $2(10 \%)$ & $2(10 \%)$ & $3(15 \%)$ \\
\hline Fuchs uveitis & $7(35 \%)$ & $6(30 \%)$ & $5(25 \%)$ \\
\hline Multiple sclerosis & $2(10 \%)$ & $4(20 \%)$ & $3(15 \%)$ \\
\hline White dot syndrome & $4(20 \%)$ & $3(15 \%)$ & $4(20 \%)$ \\
\hline
\end{tabular}

BCVA, CMT and IOP are the primary outcome variables. Standard deviations were calculated using actual $P$-values. There was no significant difference between the three groups in terms of baseline characteristics and no significant difference in results at follow-up. VA improvement was significant in group 2 in third month $0.4 \pm 0.33$. Only the first group showed a significant reduction in CMT at all weeks all cases found in our study showed either an improvement in mean visual acuity and reduction in ME by 6 months.

In group 1: total 20 eyes (six women and fourteen men) were included in the study, the mean age of the study population was $43.18 \pm 14.3$ (range: $32-60$ ) years, Baseline mean $1 \mathrm{~mm}$ CMT was $535.5 \pm 230 \mu \mathrm{M}$ (range: $345-625 \mu \mathrm{M}$ ) as measured by OCT. the medial BCVA was $1.28 \pm 0.12$, VA improved and CMT decreased slightly but not significantly after 1 month to $1.35 \pm 0.25$ and $365.3 \pm 185.5 \mu \mathrm{M}$, respectively. However, 3 months after injection, VA improved and CMT decreased to $1.71 \pm 0.37$ and $312.5 \pm 165.8 \mu \mathrm{M}$ respectively. After 6 months of follow-up, the mean BCVA had significantly increased to $1.93 \pm 0.41$ $(P=0.006)$ and retinal thickness had significantly decreased to $261.3 \pm 135 \mu \mathrm{M}(P=0.045)$ [Table 3]

Table 3: BCVA and CMT values at baseline and in the successive follow-up schedule in three group

\begin{tabular}{|c|c|c|c|c|c|c|}
\hline & \multicolumn{2}{|c|}{ Group 1} & \multicolumn{2}{|c|}{ Group 2} & \multicolumn{2}{|r|}{ Group3 } \\
\hline & V.A & CMT $(\mu \mathrm{M})$ & V.A & CMT $(\mu \mathrm{M})$ & V.A & CMT $(\mu \mathrm{M})$ \\
\hline $\begin{array}{l}\text { Baseline } \\
\text { (T0) }\end{array}$ & $1.28 \pm 0.12$ & $535.5 \pm 230 \mu \mathrm{M}$ & $\begin{array}{l}1.18 \pm \\
0.10\end{array}$ & $\begin{array}{l}510.8 \pm 240.05 \\
\mu M\end{array}$ & $\begin{array}{l}2.08 \pm \\
0.18\end{array}$ & $\begin{array}{l}525.8 \pm 245.05 \\
\mu M\end{array}$ \\
\hline $\begin{array}{l}1 \text { month } \\
\text { (T1) }\end{array}$ & $1.35 \pm 0.25$ & $\begin{array}{l}365.3 \\
\pm 185.5 \mu \mathrm{M}\end{array}$ & $1.75 \pm 0.2$ & $\begin{array}{l}470.45 \pm \\
175.20 \mu \mathrm{M}\end{array}$ & $\begin{array}{l}2.15 \pm \\
0.22\end{array}$ & $\begin{array}{l}460.45 \pm \\
185.45 \mu \mathrm{M}\end{array}$ \\
\hline $\begin{array}{c}3 \text { months } \\
\text { (T3) }\end{array}$ & $1.71 \pm 0.37$ & $\begin{array}{l}312.5 \pm \\
165.8 \mu \mathrm{M}\end{array}$ & $\begin{array}{l}1.83 \pm \\
0.33\end{array}$ & $310.5 \pm 155.7 \mu \mathrm{M}$ & $\begin{array}{l}2.63 \pm \\
0.34\end{array}$ & $320.5 \pm 165.7 \mu \mathrm{M}$ \\
\hline $\begin{array}{c}6 \text { months } \\
\text { (T6) }\end{array}$ & $1.93 \pm 0.41$ & $261.3 \pm 135 \mu \mathrm{M}$ & $\begin{array}{l}1.97 \pm \\
0.39\end{array}$ & $280.3 \pm 145 \mu \mathrm{M}$ & $\begin{array}{l}2.94 \pm \\
0.36\end{array}$ & $285.3 \pm 155 \mu \mathrm{M}$ \\
\hline
\end{tabular}

(BCVA) best-corrected visual acuity

(CMT) central macular thickness 
In group 2: total 20 eyes (five women and fifteen men) were included in the study. The mean age of the study population was $41.4 \pm 13.5$ (range: 41-65) years. Before injection of the intravitreal dexamethasone implant, all the 20 eyes included in the study had a significant edema of the retina. The average thickness of the retina at baseline was $510.8 \pm 240.05$ $\mu \mathrm{M}$, the medial BCVA was $1.18 \pm 0.10$. VA improved and CMT decreased slightly but not significantly after 1 month to $1.75 \pm 0.2$ and $470.45 \pm 175.20 \mu \mathrm{M}$, respectively. However, 3 months after implantation, VA improved and CMT decreased significantly to 1.83 \pm 0.33 and $310.5 \pm 155.7 \mu \mathrm{M}$, respectively. After 6 months of follow-up, the mean BCVA increased to 1.97 $\pm 0.39(P=0.008)$ and retinal thickness decreased to $280.3 \pm 145 \mu \mathrm{M}(P=0.040)$ [Table 3]. In group 3: total 20 eyes (six women and fourteen men) were included in the study. The mean age of the study population was $42.5 \pm 13.9$ (range: $31-68$ ) years. Before injection of the IVTA, all the 20 eyes included in the study had a significant edema of the retina. The average thickness of the retina at baseline was $525.8 \pm 245.05 \mu \mathrm{M}$, the medial BCVA was $2.08 \pm 0.18$. VA improved and CMT decreased slightly but not significantly after 1 month to $2.15 \pm 0.22$ and $460.45 \pm 185.45 \mu \mathrm{M}$, respectively. However 3 months after implantation, VA improved and CMT decreased significantly to $2.63 \pm 0.34$ and $320.5 \pm 165.7 \mu \mathrm{M}$, respectively. After 6 months of follow-up, the mean BCVA increased to $2.94 \pm 0.36$ $(P=0.075)$ and retinal thickness decreased to $285.3 \pm 155 \mu \mathrm{M}(P=0.040)$ [Table 3]

\section{Intraocular pressure}

In group 1; 20 eyes undergo intravitreally injection ranibizumab $0.5 \mathrm{mg}(0.05 \mathrm{ml})$. One dose per month (six) dose. the patients presented with a baseline IOP of $18.25 \pm 7.45 \mathrm{mmHg}$, At 1 month, 3 month, and 6 months after injection, the mean IOPs were the same and no change in the subsequent visit $19.28 \pm 8.65 \mathrm{mmHg}$, $18.29 \pm 7.49 \mathrm{mmHg}$, and $18.23 \pm 7.78 \mathrm{mmHg}$, respectively. [Table 4]

In group 2; 20 eyes undergo, Corticosteroid implants. The preoperative intraocular pressure was $18.45 \pm 6.2$ in this group Postoperative IOPs were increase significantly At 1 month $27.35 \pm 9.95 \mathrm{mmHg}$ And patient need antiglaucoma medication then decrease at 3 month mean IOPs were, $22.23 \pm 7.99 \mathrm{mmHg}$ and almost return to normal at the 6 month $18.46 \pm 6.70$ $\mathrm{mmHg}$ [Table 4]. An increase of IOP between $6 \mathrm{mmHg}$ and $15 \mathrm{mmHg}$ was maintained in 16 of 20 eyes (80\%) at 1 months and was maintained in 4 of 20 eyes at 3 months (20\%) and no cases in the 6 month [Table 5]. In group 3; 20 eyes undergo, IVTA 2 dose each per 3 month the preoperative IOP was $19.4 \pm 7.2$ in this group. Postoperative IOPs were increase at all follow up visits At 1 month, 3 month the mean IOPs were $25.35 \pm 9.65$ $\mathrm{mmHg}, 28.23 \pm 8.99 \mathrm{mmHg}$, And patient need antiglaucoma medication, 6 months after implant it decrease significantly $19.36 \pm 7.70 \mathrm{mmHg}$ [Table 4]. An increase of IOP between $6 \mathrm{mmHg}$ and $15 \mathrm{mmHg}$ was maintained in 14 of 20 eyes (70\%) at 1 months and was maintained in 12 of 20 eyes at 3 months (60\%) and no cases in the 6 months. [Table 5]

Table 4: Difference between three group in Intraocular Pressures at Baseline and Follow-up

\begin{tabular}{|c|l|l|l|}
\hline & Group 1 & Group 2 & Group 3 \\
\hline Baseline & & & \\
\hline IOP $(\mathrm{mm} \mathrm{Hg})$ & $18.25 \pm 7.45$ & $18.45 \pm 6.2$ & $19.4 \pm 7.2$ \\
\hline 1 months & & & \\
\hline IOP $(\mathrm{mm} \mathrm{Hg})$ & $19.28 \pm 8.65$ & $27.35 \pm 9.95$ & $25.35 \pm 9.65$ \\
\hline 3 month & & & \\
\hline IOP $(\mathrm{mm} \mathrm{Hg})$ & $18.29 \pm 7.49$ & $22.23 \pm 7.99$ & $28.23 \pm 8.99$ \\
\hline 6 months & & & \\
\hline IOP $(\mathrm{mm} \mathrm{Hg})$ & $18.23 \pm 7.78$ & $18.46 \pm 6.70$ & $19.36 \pm 7.70$ \\
\hline
\end{tabular}

Table 5: Percentage of IOP increase in three group

\begin{tabular}{|l|c|c|c|}
\hline & Group 1 & Group 2 & Group 3 \\
\hline month & & & \\
\hline From 6-15mmHg & 0 & $16(80 \%)$ & $14(70 \%)$ \\
\hline months & & & \\
\hline From 6-15mmHg & 0 & $4(20 \%)$ & $12(60 \%)$ \\
\hline months & & & \\
\hline From 6-15mmHg & 0 & 0 & 0 \\
\hline
\end{tabular}

\section{Complications}

There were no intraoperative complications in either of any group. Also no patient in any group show endophthalmitis, perforation of the eye, conjunctival hemorrhage, and cataract progression except in two elderly patients with repeated injections in group 3 .

\section{DISCUSSION}

The goal for treatment of non-infectious uveitis is three-fold: 1) resolve intraocular inflammation, 2) achieve remission and prevent recurrences, and 3) preserve vision and prevent ocular complications. Corticosteroids are the first-line treatment for noninfectious uveitis and are effective for acute inflammation ${ }^{(\mathbf{1 1})}$. This study was performed to evaluate the efficacy of Intravitreal Injection of ranibizumab, 
Comparison Between Intravitreal Ranibizumab Injection...

Corticosteroid implants and IVTA injection in treatment of noninfectious uveitic ME, total 60 eyes of 45 uveitic patients included in this study all patients in group 1 received six injection $0.5 \mathrm{mg}(0.05 \mathrm{ml})$ dose of intravitreal Lucentis one /dose per month Second group 20 eyes undergo, Corticosteroid implants Third group undergo IVTA injection of $4 \mathrm{mg}$ each dose per 3 months.

In this study the three treatment groups were similar regarding age, sex, type of uveitis, and baseline ocular characteristics including VA, ME Thickness. The etiology of uveitis was established in $75 \%$ of all cases and was not established in $25 \%$ in all groups.

BCVA, CMT and IOP are the primary outcome variables. Standard deviations were calculated using actual $P$-values. There was no significant difference between the three groups in terms of baseline characteristics.

The results showed that multiple injection 0.5 $\mathrm{mg}(0.05 \mathrm{ml})$ of intravitreal ranibizumab for six month was associated with a significant and constant improvement in BCVA and with a marked reduction of CMT $(535.5 \pm 230 \mu \mathrm{M}$ at baseline compared with 261.3 $\pm 135 \mu \mathrm{M}(P=0.045)$ after 6 months of follow-up, in $90 \%$ of the patients which is nearly similar that was demonstrated in the study by Campochiaro et al. ${ }^{(12)}$. In this study in group 1: VA improved and CMT decreased slightly but not significantly after 1 month to $1.35 \pm 0.25$ and $365.3 \pm 185.5 \mu \mathrm{M}$, respectively. . However, 3 months after injection, VA improved and CMT decreased to $1.71 \pm 0.37$ and $312.5 \pm 165.8 \mu \mathrm{M}$ respectively. After 6 months of follow-up, the mean BCVA had significantly increased to $1.93 \pm 0.41$ $(P=0.006)$ and retinal thickness had significantly decreased to $261.3 \pm 135 \mu \mathrm{M}(P=0.045)$ this is better than the result of Cordero et al. ${ }^{(13)}$.

In this study in group 2, VA improved and CMT decreased after 1 month to $1.75 \pm 0.2$, and reduction of CME was greater in this group compared to the $3^{\text {rd }}$ group $(P<0.01)$. This coincide with the result of Callanan et al. ${ }^{(\mathbf{1 4})}$. However, 3 months after implantation, VA improved to $1.83 \pm 0.33$ this is better than the result of Kuppermann et al. ${ }^{(15)}$.

Dexamethasone implant induced an improvement of VA, as measured by ETDRS, after one, three, four, and six months from implants. This is coincide with the result in study by Haller et al..$^{(16)}$.

Meyer et al. ${ }^{(17)}$ stated that the greatest efficacy of dexamethasone is obtained within the first three months. After that, its therapeutic efficacy slowly decreases, although this effect is more pronounced in CMT than in BCVA measurements. These findings are in line with other reports showing that the anti- inflammatory action of dexamethasone is rapid and may produce beneficial effects within the first week of treatment. Regarding dexamethasone safety profile, no particular complications resulting from either the implant or the drug itself were found, unless increase of IOP a result in accordance with Kuppermann et al. ${ }^{(18)}$.

In this study in group 3, VA improved and CMT decreased slightly but not significantly after 1 month to $2.15 \pm 0.22$ and $460.45 \pm 185.45 \mu \mathrm{M}$, respectively. However 3 months after implantation, VA improved and CMT decreased significantly to $2.63 \pm$ 0.34 and $320.5 \pm 165.7 \mu \mathrm{M}$, respectively. After 6 months of follow-up, the mean BCVA increased to 2.94 $\pm 0.36(P=0.075)$ and retinal thickness decreased to $285.3 \pm 155 \mu \mathrm{M}(P=0.040)$.

Couch and Bakri et al. and Cunningham et al. suggest many of the studies using IVTA control intraocular inflammation but these effects appeared to be weak or transient, therefore, reinjection is often required ${ }^{(19,20)}$.

Kok et al. ${ }^{(21)}$ found that TA was effective in reducing CME with significant improvement in BCVA (0.65-0.39 log MAR), especially in patients $\leq 60$ years of age, but rise in IOP was observed in $43 \%$ of subjects. In this study in [group 1], the patients presented with a baseline IOP of $18.25 \pm 7.45 \mathrm{mmHg}$, At 1 month, 3 month, and 6 months after injection the mean IOPs were the same and no change occur in the subsequent visit this the same result of Gulati's et al. ${ }^{(\mathbf{2 2})}$. In this study in [group 2], the preoperative IOP was $18.45 \pm 6.2$ in this group postoperative IOPs were increase significantly at 1 month $27.35 \pm 9.95 \mathrm{mmHg}$ and patient need antiglaucoma medication then decrease at 3 month mean IOPs were, $22.23 \pm 7.99 \mathrm{mmHg}$ and almost return to normal at the 6 month $18.46 \pm 6.70 \mathrm{mmHg}$.

An increase of IOP between $6 \mathrm{mmHg}$ and 15 $\mathrm{mmHg}$ was maintained in 16 of 20 eyes $(80 \%)$ at 1 months and was maintained in 4 of 20 eyes at 3 months (20\%) this the same percentage of Shrestha et al. $^{(\mathbf{2 3})}$ that reported the incidence of OHT in 116 consecutive new uveitis patients that were followed through 6 weeks to be $20 \%$, mostly corticosteroids-induced.

In this study In [group 3], The preoperative IOP was $19.4 \pm 7.2$ in this group Postoperative IOPs were increase at all follow up visits At 1 month, 3 month the mean IOPs were $25.35 \pm 9.65 \mathrm{mmHg}, 28.23 \pm 8.99$ $\mathrm{mmHg}$, And patient need antiglaucoma medication. 6 months after implant, it decreases significantly $19.36 \pm$ $7.70 \mathrm{mmHg}$ this result coincide with the result of Kiddee et al. ${ }^{\text {(24) }}$.

In comparison between group 2 and 3 there were equivalent in their ability to prevent recurrence of non-infectious uveitis, improve VA, and reduced 
inflammation but the side effect was more favorable for group 3.

\section{CONCLUSION}

Our study demonstrated that Intravitreal injection can be used as a single therapy to treat uveitic ME secondary to noninfectious uveitis, With a variety of intravitreal therapeutic agents available for treatment of uveitic ME in this study (Intravitreal ranibizumab injection, corticosteroid implants and IVTA injection), each drug having its own advantages and disadvantages, the final treatment should be individualized based on the severity of disease, risk /benefit ratio of each therapy and choice of the patient. Corticosteroids either implant or injection remains the mainstay of treatment.

\section{REFERENCE}

1. Jabs DA, Nussenblatt RB and Rosenbaum JT (2005): Standardization of uveitis nomenclature for reporting clinical data. Results of the First International Workshop. American Journal of Ophthalmology, 140(3):509-516.

2. Kim SJ (2011): Diagnosis and management of noninfectious pediatric uveitis. International Ophthalmology Clinics, 51(1):129-145.

3. Kempen JH, Altaweel MM, Holbrook JT et al. (2011): Multicenter Uveitis Steroid Treatment (MUST) Trial Research Group. Randomized comparison of systemic anti-inflammatory therapy versus fluocinolone acetonide implant for intermediate, posterior, and panuveitis: The multicenter uveitis steroid treatment trial. Ophthalmology, 118:1916-26.

4. Koronis $\mathbf{S}$, Stavrakas P, Balidis $M$ et al. (2019): Update in treatment of uveitic macular edema. Drug Des Devel Ther., 13:667-680.

5. Acharya NR, Hong KC, Lee SM et al. (2009): Ranibizumab for refractory uveitis-related macular edema. Am J Ophthalmol., 148:303-9.

6. Lowder C, Belfort R, Lightman $\mathrm{S}$ et al. (2011): Dexamethasone intravitreal implant for noninfectious intermediate or posterior uveitis. Arch Ophthalmol., 129:545-53.

7. Beer PM, Bakri SJ, Singh RJ et al. (2003): Intraocular concentration and pharmacokinetics of triamcinolone acetonide after a single intravitreal injection. Ophthalmology, 110:681-6.

8. Chan A, Leung LS, Blumenkranz MS (2011): Critical appraisal of the clinical utility of the dexamethasone intravitreal implant (Ozurdex) for the treatment of macular edema related to branch retinal vein occlusion or central retinal vein occlusion. Clin Ophthalmol., 5:1043-9.

9. Chang-Lin JE, Attar M, Acheampong AA et al. (2011): Pharmacokinetics and pharmacodynamics of a sustainedrelease dexamethasone intravitreal implant. Invest Ophthalmol Vis Sci., 52:80-6.
10. Bae JH, Lee CS, Lee SC (2011): Efficacy and safety of intravitreal bevacizumab compared with intravitreal and posterior sub-tenon triamcinolone acetonide for treatment of uveitic cystoid macular edema. Retina, 31:111-8.

11. Gregory AC, Kempen JH, Daniel E et al. (2010): Risk factors for loss of visual acuity among patients with uveitis associated with juvenile idiopathic arthritis: the Systemic Immunosuppressive Therapy for Eye Diseases Study. Ophthalmology, 120(1):186-192.

12. Campochiaro PA, Heier JS, Feiner L et al. (2010): Ranibizumab for macular edema following branch retinal vein occlusion: six-month primary end point results of a phase III study. Ophthalmology, 117:1102-1112.

13. Cordero M, Sobrin L, Onal Set al. (2007): Intravitreal bevacizumab for treatment of uveitic macular edema. Ophthalmology, 114:1574-9.e1.

14. Callanan DG, Jaffe GJ, Martin DF et al. (2008): Treatment of posterior uveitis with a fluocinolone acetonide implant: three-year clinical trial results. Arch Ophthalmol., 126:1191-1201.

15. Kuppermann BD, Blumenkranz MS, Haller JAet al. (2007): Randomized controlled study of an Intravitreous dexamethasone drug delivery system in patients with persistent macular edema. Dexamethasone DDS Phase II Study Group. Arch Ophthalmol., 125:309-317.

16. Haller JA, Dugel P, Weinberg DVet al. (2009): Evaluation of safety and performance of an applicator for a novel intra-vitreal dexamethasone drug delivery system for the treatment of macular edema. Retina, 29:46-51.

17. Meyer CH, Klein A, Alten F et al. (2012): Release and velocity of micronized dexamethasone implants with an intravitreal drug delivery system: kinematic analysis with a high-speed camera. Retina,32(10):2133-40.

18. Kuppermann BD, Chou C, Weinberg DVet al. (2010): Dexamethasone DDS Phase II Study Group. Intravitreous dexamethasone effects on different patterns of diabetic macular edema. Arch Ophthalmol., 128(5):642-3.

19. Couch SM, Bakri SJ (2009): Intravitreal triamcinolone for intraocular inflammation and associated macular edema. Clin Ophthalmol. , 3:41-47.

20. Cunningham M, Edelman $J$, Kaushal $S$. Intravitreal steroids for macular edema: the past, the present, and the future. Surv Ophthalmol., 53:139-149.

21. Kok H, Lau C, Maycock Net al. (2005): Outcome of intravitreal triamcinolone in uveitis. Ophthalmology, 112:1-7.

22. Gulati N, Forooghian F, Lieberman Ret al. (2011): Vascular endothelial growth factor inhibition in uveitis: a systematic review. Br J Ophthalmol.,95:162-165.

23. Shrestha S, Thapa M, Shah DN (2014): Pattern of intraocular pressure fluctuation in uveitic eyes treated with corticosteroids. OculImmunolInflamm.,22:110-15.

24. Kiddee W, Trope GE, Sheng Let al. (2013):Intraocular pressure monitoring post intravitreal steroids: A systematic review. Surv Ophthalmol., 58:291-310. 